\title{
Catalytic Feedstock Recycling of Polymers
}

\section{A Green Approach Towards Sustainable Environment}

\author{
Raju Francis ${ }^{1}$, Beena Sethi ${ }^{2}$ \\ ${ }^{1}$ Department of chemistry, MahatamaGandhi University, Kottayam, Kerala, India \\ ${ }^{2}$ Department of chemistry, K.L. Mehta Dayanand College for Women, Faridabad, Haryana, India \\ Email: rajufrancis@yahoo.com, beena_sethi@rediffmail.com
}

Received 2012

\begin{abstract}
This piece of study involves degradation of plastic waste in presence of two different catalysts. It was found in gas chromatography (GC) analysis results that in presence of these catalysts more than $80 \%$ of polymer by weight was converted into either liquid or gaseous hydrocarbons. These can be utilized as fuel or can be transformed into other useful products. Thermo gravimetric analysis (TGA) and differential scanning calorimetric (DSC) analysis of polymers suggest that presence of these catalysts lowers degradation temperature and change mechanism of degradation.
\end{abstract}

Keywords: Polymer Degradation; Catalyst; Green Chemistryr; Feedstock Recycling; GC; TGA; DSC

\section{Introduction}

Polyolefins (polyethylene, polypropylene, polystyrene) are plastic materials used extensively in containers and packing. Polyethylene (PE) is the worldwide most produced polymer with about 60 million tons per year and the main component of plastic waste [1-3]. Other than PE polypropylene (PP), polyvinyl chloride (PVC) and polystyrene are the main components of solid waste [4-6]. They present approximate $60 \%$ of the total solid plastic waste generated in urban solid waste[1].

The current strategies to deal with solid plastic waste (around $62 \%$ of total available solid waste is collectable) are still based on land filling and incineration without energy recovery [7]. Because of this huge plastic solid waste many municipal cities are facing disposal problems such as emission of toxic substances (dioxins and furanes) on incineration and shortage of landfill sites [8].

Plastic material has almost same composition to petroleum and they are high yielding energy sources. For example one liter of heating oil has a net calorific value of 10,200 Kcal, whereas $1 \mathrm{Kg}$ of plastic releases 11,000 ,Kcal worth of energy. $1 \mathrm{Kg}$ briquettes (blocks of pressed coal dust) have a net calorific value of 4,800 Kcal only. So it can be recycled into petroleum products safely with suitable technique without producing any harmful gases [9-12]. At one side it will provide sustainable alternative of energy recovery and material recovery and other side society will get rid from the disposal problem of plastic waste.

Polyethylene (PE) and polypropylene (PP) as typical commodity plastics are better known as randomly degrading polymers rather than depolymerizing polymers [13]. This is not surprising because the heat of polymerization, an important parameter for estimating the depolymerizability of polymers, has larger negative values for ethylene and propylene, than for styrene (St) and methyl methacrylate, indicating the difficulty in depolymerising PE and PP [14]. However, cases in which the zip length is controlled by chain-transfer reactions and in which the activation energy value for a depolymerisation reaction, such as $\beta$-scission, is higher than that of the chain-transfer reactions, the monomer yield can be increased with increase in temperature.

Many methods have been investigated by different researchers for feed stock recycling. These are broadly divided into two categories as mechanical recycling and chemical recycling methods. A promising method for the reprocessing of waste plastic is feedstock recycling, or clean incineration of municipal solid waste which allows the conversion of plastic residues into raw chemicals, monomers of plastics and hydrocarbon feedstock It is a sustainable way for the recovery of the organic content from polymeric waste and also to preserve petroleum resources in addition to protecting environment [13-15].

In spite of many $R \& D$ projects over the three decades, it is reported that recycling of waste plastic in oil production process covers negligible amount in the total amount of waste plastic generated all over the world. Moreover these methods are economically not good due to technical problems such as low treatment ability of techniques and high energy consumptions and low quality of products obtained. The produced oils have limited uses and applications only in industrial boilers, burners and power generators. And the fuel gas generated by plastic recycling is two or three times more expensive than fuel oil [16].

So, it is correct time to develop more economic, safe, ecofriendly and sustainable method for feedstock recycling of waste polymer.

In this study, attempts are taken to obtain useful products and virgin monomer by degradation of polymers in presence of different catalysts without generation of any further hazardous/poisonous chemicals at low temperature.

\section{Materials and Methods}

\subsection{Linear Low Density Polyethylene (LLDPE)}


It was purchased B.R. Scientific and Chemicals Company, Faridabad, Haryana. It was washed and dried in open air for one day. After that it was used for practical purposes. It was soaked in solvent for three days then warmed to get it liquid state.

\subsection{Toluene, Transition Metal Oxideand Nonmetal Oxide}

These entire chemicals are also purchased from B. R. Scientific and Chemicals Company, Faridabad, Haryana. These all were used without further purification.

\subsection{Preparation of Films of Polymers Samples}

Films of polymer samples are prepared by dissolving polymer into solvent in presence of weighed amount of desired catalyst and dried in oven at $330 \mathrm{~K}$.

\subsection{TGA and DSC Analysis}

TGA and DSC analysis of pure polymer and in presence of catalyst was carried out at North Maharashtra University, Jalgaon, Maharashtra. All these analyses were carried out on Shimadzu DSC- 60 \& Shimadzu TGA- 60 WS.

\subsection{GC Analysis}

The GC studies were carried out in a special GC-MS instrument equipped with gas sample injector. This facility was kindly provided by Mahatma Gandhi University, Kottayam.

\section{Result and Discussion}

We were interested to obtain useful products and virgin monomer by degradation of polymers in presence of different catalysts at low temperature. We observed certain catalysts decrease the degradation temperature of polymers. Further in presence of these catalysts polymer degrades in more than one step while in absence of these catalysts they show decomposition in one step at little higher temperature thus decrease the reaction temperature. The quality of degradation products is improved as well as percentage of dioxins and aromatic compounds are decreased. These harmful products and aromatics are generally produced at high temperature (above $600^{\circ} \mathrm{C}$ ).

Preliminary TGA data presented in Figures 1 \& $\mathbf{2}$ shows that there is considerable increase in the thermal decomposition of polymer sample when cracked in presence of catalyst A in comparison to catalyst B. From the graph it can be seen that in the former case the weight loss is $36 \%$ whereas in the latter case it is only $20 \%$. The amount of catalyst required for this change is only $10 \%$ of the total polymer mass.. However the onset of decomposition temperature remains the same in both cases. Nevertheless the interesting point is the substantial drop in the decomposition temperature to $\sim 220^{\circ} \mathrm{C}$, in the presence of catalyst (Figures 1 \& 2). We also observed the possibility of decreasing the catalyst amount and its reusability for this cracking experiment.

The DSC results showed a marked effect on the ability of catalyst to effect the endothermic decomposition process. This is can be clearly distinguished from the sluggish and sharp changes in DSC profiles at the decomposition temperature in absence and presence of catalyst (Figures 3-5).

To get these tests polymer (LLDPE) was mixed with catalyst physically in presence of solvent then a film was prepared for analysis.

TGA and DSC were carried out each time prior to GC analysis. This gave information of number of steps involved in each reaction and gave information of optimum and starting temperature for each step of reaction.

To test obtained degradation products GC analysis of effluent gases was carried out in absence and presence of catalysts. Results obtained are given in Table 1. The GC studies were carried out in a special GC-MS instrument equipped with gas sample injector.

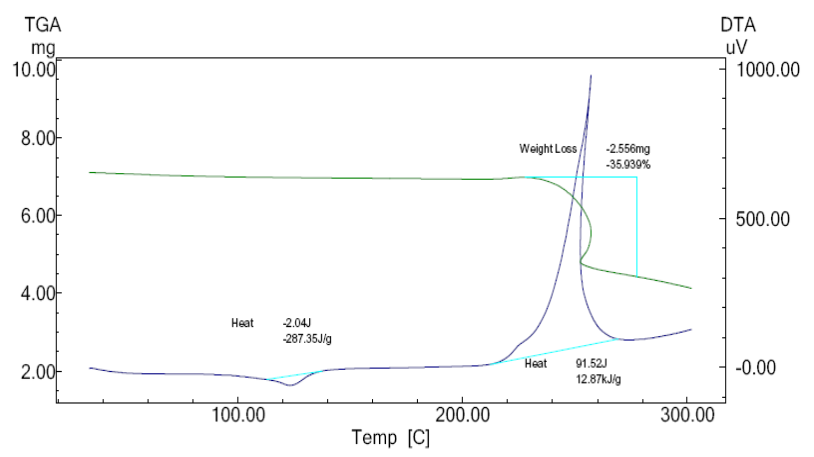

Figure 1. TGA of polymer in presence of catalyst $A$.

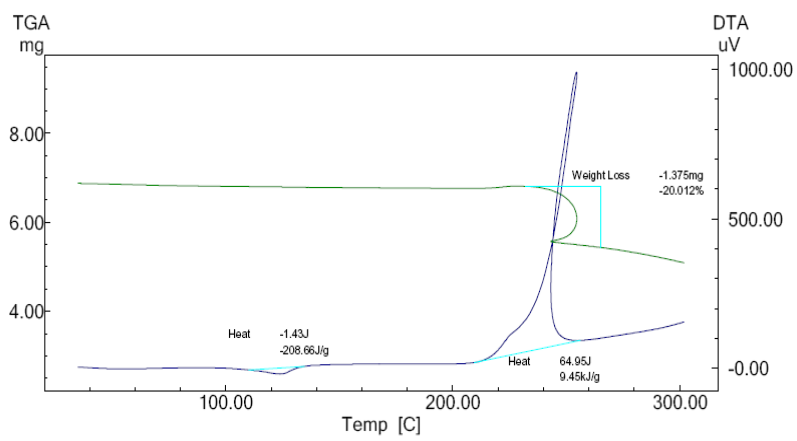

Figure 2. TGA of polymer in presence of catalyst B.

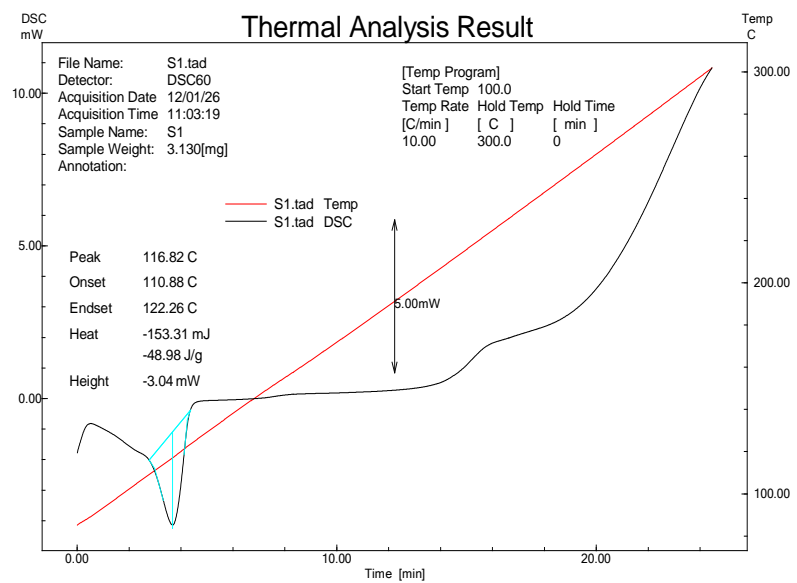

Figure 3. DSC of polymer in absence Catalyst. 


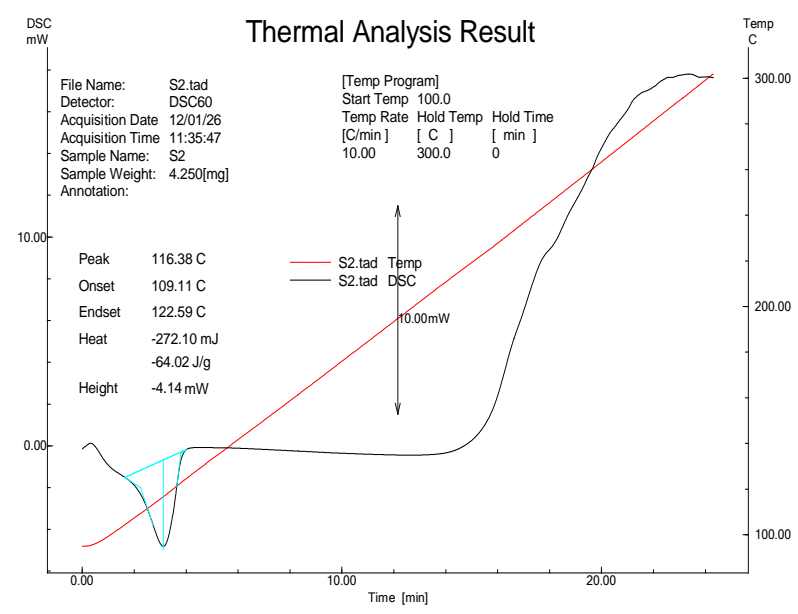

Figure 4. DSC of polymer in presence Catalyst A.

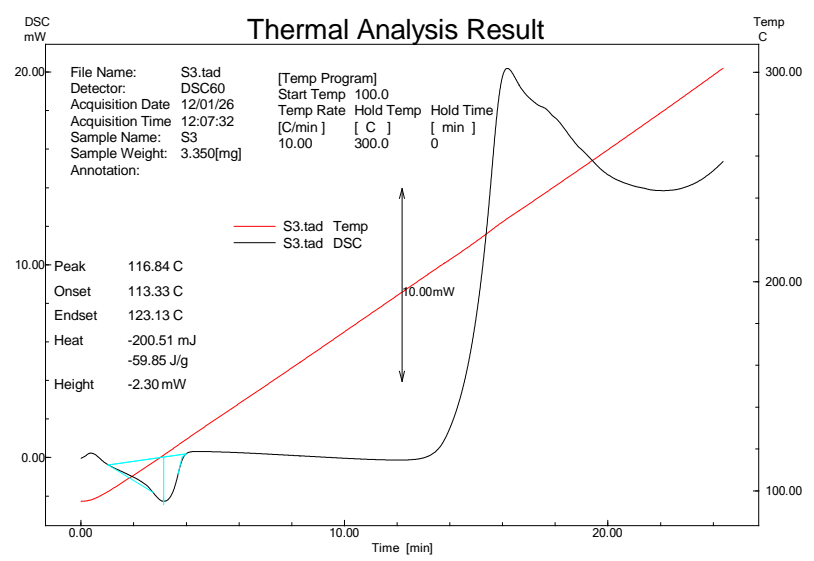

Figure 5. DSC of polymer in presence Catalyst B.

Table 1. G C analysis of fragments obtained during catalytic cracking of LLDPE.

\begin{tabular}{ccccc}
\hline \multirow{2}{*}{$\begin{array}{c}\text { Carbon } \\
\text { fragment }\end{array}$} & \multicolumn{4}{c}{ Sample } \\
\cline { 2 - 5 } & $\begin{array}{c}\text { Polymer + cat } \\
\text { A }\end{array}$ & $\begin{array}{c}\text { Polymer }+ \text { cat } \\
\text { B }\end{array}$ & $\begin{array}{c}\text { Polymer + cat } \\
\text { A+B }\end{array}$ & $\begin{array}{c}\text { Pure } \\
\text { Polymer }\end{array}$ \\
\hline $\begin{array}{c}\text { C3/C4 } \\
\text { (wt\%) }\end{array}$ & 72.3 & 82.5 & 72.9 & 32.4 \\
$\begin{array}{c}\text { C5/C6 } \\
(w t \%)\end{array}$ & 0 & 1.5 & 7.2 & 12.0 \\
$\begin{array}{c}\text { C7 } \\
(w t \%)\end{array}$ & 5.5 & 14.5 & 1.7 & 1.2 \\
$\begin{array}{c}\text { C8 } \\
(w t \%)\end{array}$ & 9.2 & 0 & 14 & 37 \\
$\begin{array}{c}\text { C9 } \\
(w t \%)\end{array}$ & 0 & 0 & 0 & 16.4 \\
$\begin{array}{c}\text { C10 } \\
(w t \%)\end{array}$ & 3.0 & 1.5 & 4.2 & 1.0 \\
$>$ C10 & 10 & 0 & 2 & 0 \\
$(w t \%)$ & 10 & 0 & & \\
\hline
\end{tabular}

GC results of degraded products show that in presence of catalyst A, B and in presence of both, percentage of C3- C4 hydrocarbons is very high while percentage of higher hydrocarbons (above $\mathrm{C} 10$ ) is almost negligible.

It is found that on degradation of pure polymer results only 32\% C3-C4 hydrocarbons while, in presence of catalyst A and B percentage of C3-C4 hydrocarbon was 72 and 82 respectively. GC analysis of polymer in presence of both catalysts together also gave high percentage of C3- C4 hydrocarbons and low percentage of higher hydrocarbons.

To get good quality of products by varying dose of catalysts, admixtures, temperature and rate of heating is still required. Attempts will be made to use nano particles of catalyst to check catalytic activity of catalyst in future.

Activity of catalyst and possibility of recyclization of catalysts will also be tested by some methods. Attempts will be made to get maximum fraction of monomer and gaseous fraction.

All the above studies encouraged us and created lot of interest to pursue further the degradation of polymer in presence of catalysts.

\section{Conclusion}

From the experimental findings of the present work, the following conclusion can be drawn:

1. Pure polymer degrades at much higher temperature and it involves single step in association of production of green house and toxic gases like dioxin.

2. In presence of catalyst $\mathrm{A}$ and $\mathrm{B}$, degradation temperature lowers and degradation reaction involves more than one steps.

3. Degradation of pure polymer produces only 32\% C3/C4 hydrocarbons and 12\% C5/C6 hydrocarbons.

4. In presence of catalyst A and B degradation of polymer produces $72 \%$ and $82 \%$ C3/C4 hydrocarbons respectively.

5. Adjusting dose of catalyst, use of nano particles and recycling of catalyst can make this catalytic feedstock recycling method a good tool to get sustainable environment.

This can help to get sustainable source of petroleum products.

\section{Acknowledgements}

Author sincerely thank to Dr. R.D. Kulkarni, Professor in Chemistry, Department of polymer science, N.M. University, Jalgaon, Maharashtra, giving facility of TGA and DSC analyzers to carry out this study successfully.

\section{REFERENCES}

[1] K. C Kirkwood, S. A Leng, and David, "Stem cracking of unconventional hydrocarbon feedstocks for production of petrochemicals”. Proceedings of 45th International Petroleum Conference June 13, 2011, Bratislava, Slovak Republic.

[2] J. Walenzievski, "Continuous flow cracking of waste plastics". Fuel Process. Technol. vol. 86, pp. 1265- 1272, 2005.

[3] W. Kaminsky, and F. Hartman, "Simulation and experiments of polyethene pyrolysis in a Fuildized Bed Process". Proceedings of III International Symphosium of Feedstock Recycling of Plastics and other Innovative Recycling Techniques. Karlsruhe, Germany, Sept 25-29, (2000). pp 201.

[4] M. Predel, and W. Kaminsky, "Feedstock recycling of polymers 
by pyrolysis in a fluidised bed”. Polymer. Degradation Stabil. vol.70, pp. 373-378, (2000).

[5] P. T. Williams, and E. A. Williams, "Pyrolysis of post consumed waste plastics for the recovery of btx-aromatics using a fluidized bed reactor”. J. Anal. Appl. Pyrolysis, vol. 51, pp. 107-112, 1999.

[6] W. Kaminsky, and H. Sinn, "Recycling and Recovery of Plastics, Hanser, New York" . Proceedings of III International Symphosium of Feedstock Recycling of Plastics and other Innovative Recycling Techniques. Karlsruhe, Germany, Sept 25-29, pp 435-442. 2005.

[7] J. Aguado, and D. P. Serrano,"European trends in the feedstock recycling of plastic”. Global NEST Journal, vol. 9(1), pp 12-19, 2007

[8] P. Connet, "Muncipal waste incineration: A poor solution for twenty first century". Journal of the Air \& Waste Management Association, vol. 56, pp. 709-742, 2006.

[9] J. Aguado, and D. P. Serrano, "Feedstock Recycling of Plastic Wastes". Cambridge: Royal Society of Chemistry. 1999.

[10] D. P. Serrano, J. Aguado, G. Vicente, N. Sanchez, and L. Estebon, "Enhanced Production of $\alpha$-Olefins by thermal degradation of HDPE in De Calin Solvent”. 2000.

[11] S. Suga, Y. Wakayama, and T. Funazukuri, "Hydrothermal dechlorination of Poly (vinylchloride) in the absence and the presence of hydrogen peroxide”. Polym, Degrad, Stab. vol. 67, pp. 285 -298, 2000.

[12] R. Maraghi, Disposal, recycling and reuse. In Mosta Fa N.; Dekker, M. Editors, Plastic Waste Management. New York, USA; pp 223-226. 1993.

[13] I. Mita, Effect of structure on degradation and stability of polymers. In Aspect of Degradation and Stabilization of Polymers (ed. Jellinek, H. H. G.) 1978, Ch. 6, 247-294 (Elsevier, Amsterdam).

[14] J. Leonard, Heats and entropies of polymerization, ceiling temperatures, equilibrium monomer concentrations, and polymerizability of heterocyclic compounds. In Polymer Handbook Fourth Edition (eds, Brandrup, J., Immergut, E. H., \& Grulke, E. A.) Ch. II, 363-414 (Wiley Interscience, New York, 1999).

[15] S. Kumar, A. K. Panda, and R. K. Singh. "A review on tertiary recycling of high- density Poly ethylene to fuel". Conservation and Recycling, vol. 55, pp. 893-910, 2011.

[16] Uemichi, Y. Makino, and T. Kanazuka, "Degradation of polypropylene to aromatic hydrocarbons over Pt- and Fe-containing activated carbon catalysts”. J. Anal. Appl. Pyrol. vol.16, pp. 229-232, 1989. 